\title{
Investigation of Residual Anode Material after Electrorefining Uranium in Molten Chloride Salt
}

\author{
M. A. Rose ${ }^{\mathrm{a}, \mathrm{b}, *}$, M. A. Williamson ${ }^{\mathrm{b}}$, and J. Willit ${ }^{\mathrm{b}}$ \\ ${ }^{a}$ Department of Nuclear Engineering, Purdue University, West Lafayette, Indiana, 47907 \\ ${ }^{\mathrm{b}}$ Nuclear Engineering Division, Argonne National Laboratory, Argonne, Illinois 60439
}

\begin{abstract}
A buildup of material at uranium anodes during uranium electrorefining in molten chloride salts has been observed. Potentiodynamic testing has been conducted using a three electrode cell, with a uranium working electrode in both $\mathrm{LiCl} / \mathrm{KCl}$ eutectic and $\mathrm{LiCl}$ each containing $\sim 5 \mathrm{~mol} \% \mathrm{UCl}_{3}$. The anodic current response was observed at $50^{\circ}$ intervals between $450^{\circ} \mathrm{C}$ and $650^{\circ} \mathrm{C}$ in the eutectic salt. These tests revealed a buildup of material at the anode in $\mathrm{LiCl} / \mathrm{KCl}$ salt, which was sampled at room temperature, and analyzed using ICP-MS, XRD and SEM techniques. Examination of the analytical data, current response curves and published phase diagrams has established that as the uranium anode dissolves, the $\mathrm{U}^{3+}$ ion concentration in the diffusion layer surrounding the electrode rises precipitously to levels, which may at low temperatures exceed the solubility limit for $\mathrm{UCl}_{3}$ or in the case of the eutectic salt for $\mathrm{K}_{2} \mathrm{UCl}_{5}$. The reduction in current response observed at low temperature in eutectic salt is eliminated at $650^{\circ} \mathrm{C}$, where $\mathrm{K}_{2} \mathrm{UCl}_{5}$ is absent due to its congruent melting and only simple concentration polarization effects are seen. In $\mathrm{LiCl}$ similar concentration effects are seen though significantly longer time at applied potential is required to effect a reduction in the current response as compared to the eutectic salt.
\end{abstract}

\section{Introduction}

Many researchers have reported a residue or heel in the anode of electrorefiners after uranium electrorefining, which contains a significant quantity of undissolved uranium metal. A loosely adhering discolored salt coating the materials removed from the anode after uranium electrorefining has been observed as well. Iizuka observed this phenomenon during electrorefining of U-Zr alloys [1,2]. Research at Argonne National Laboratory has revealed a similar material forming on pure uranium metal and on U-Mo alloys $[3,4]$.

During electrorefining, the formation of this material reduces operating currents. A two-step rise in potential as the electrorefiner begins operation has been observed as this material forms suggesting the formation of the material may be potential dependent $[2,4]$. This material was so disruptive to electrorefiner performance that lizuka et al. developed a process to recover the uranium left in the anode residue via distillation [5]. lizuka attributed the observed behavior to the formation of multiple diffusion layers and postulated the formation of insoluble $\mathrm{UCl}_{3}$ in the pores of the outer layer due to the solubility limit being exceeded during the dissolution of uranium from the alloy $[1,2]$. This explanation does not account for the observation of similar material and similar potential dependent behavior with pure uranium electrodes.

* Corresponding Author at Argonne National Laboratory 9700 S. Cass Ave, Argonne, IL 60439, U.S.A. Tel: +1 6302523239

Email Address: marose@anl.gov 
Previously work was done examining the response of a uranium electrode at low overpotentials, in the pre-Tafel region to determine the exchange current density and Tafel parameters for the $\mathrm{U} / \mathrm{U}^{3+}$ couple in the $\mathrm{LiCl} / \mathrm{KCl}-\mathrm{UCl}_{3}$ [6]. Significantly reduced currents were observed at the highest potentials of the pre-Tafel region. To expand upon that work, investigation of the system at higher overpotentials was completed. Understanding the composition of the material forming at uranium anodes as well as its mechanism of formation will yield a more complete understanding of uranium electrorefining in these molten salt systems.

\subsection{Film Production and Sampling}

\section{Materials and Methods}

A three electrode cell was used to study the formation of and create the anode film previously observed. A $6 \mathrm{~mm}$ diameter uranium rod mounted by compression fittings to a steel lead was used as a w orking electrode, a tungsten rod functioned as the counter electrode and the reference electrode consisted of $\mathrm{Ag} / 0.42 \mathrm{~mol} \% \mathrm{AgCl}$ housed in a mullite tube. The height of the working electrode exposed to the salt was carefully controlled using a micrometer slide, keeping the exposed surface area below $2.25 \mathrm{~cm}^{2}$ for all tests. A photo of the $6 \mathrm{~mm}$ diameter uranium working electrode prior to testing is shown in Figure 1. The current and potential of the cell were controlled and monitored using a Solartron 1285 potentiostat. Cell temperature was measured with a type-K thermocouple. The cell electrolyte comprised $\mathrm{LiCl}-\mathrm{KCl}$ eutectic or $\mathrm{LiCl}$, each with approximately $5 \mathrm{~mol} \% \mathrm{UCl}_{3}$. The potentiodynamic response of the working electrode was examined under an inert helium atmosphere, maintained at $<15 \mathrm{ppm}_{2}$ and $<1 \mathrm{ppm}_{2} \mathrm{O}$.

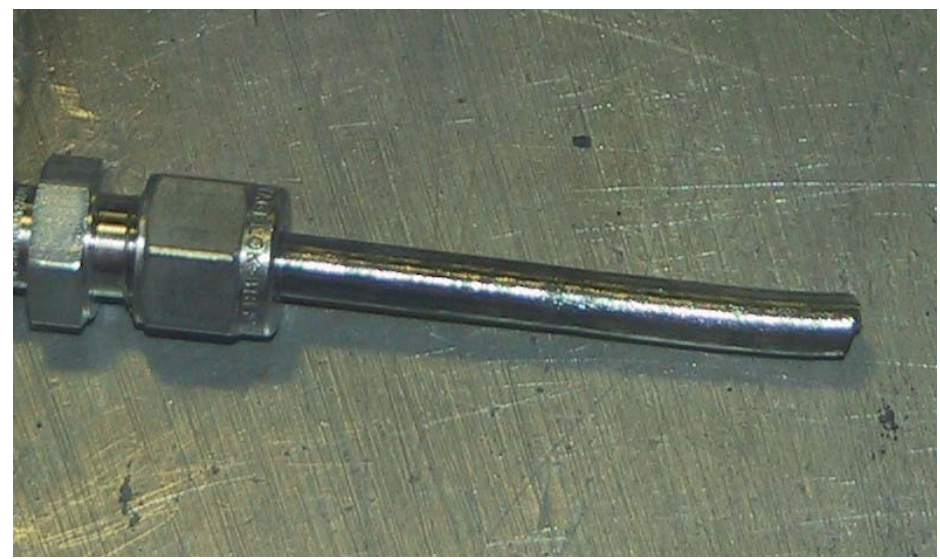

Figure 1: Uranium Working Electrode Prior to Potentiodynamic Testing.

Potentiodynamic scans (PDS) were conducted in both anodic and cathodic directions between $450^{\circ}$ and $650^{\circ} \mathrm{C}$ in $50^{\circ}$ intervals at scan rates of $1.0,0.166$ and 0.1 $\mathrm{mV} / \mathrm{s}$ in the eutectic salt. Anodic tests were conducted from $-0.05 \mathrm{~V}$ to $0.5 \mathrm{~V}$ overpotential, while cathodic tests were conducted from $0.05 \mathrm{~V}$ to $-0.5 \mathrm{~V}$ overpotential. A final anodic test was completed at $0.01 \mathrm{mV} / \mathrm{s}$ at $500^{\circ} \mathrm{C}$. The tests resulted in a significant amount of material or salt film remaining on the surface of the uranium electrode. A sample of the material on the anode was collected by light abrasion with a steel file. In preliminary tests, a salt sample was taken from a uranium counter electrode of approximately 0.5

* Corresponding Author at Argonne National Laboratory 9700 S. Cass Ave, Argonne, IL 60439, U.S.A. Tel: +1 6302523239

Email Address: marose@anl.gov 
inches in diameter that had been treated as an anode, while the cathodic response of a uranium deposit on a tungsten working electrode was examined. This sample was also collected by abrasion with a steel file.

For comparison, a PDS of a second $6 \mathrm{~mm}$ uranium rod was conducted in a $\mathrm{LiCl}$ electrolyte containing approximately $5 \mathrm{~mol} \% \mathrm{UCl}_{3}$. The PDS were conducted at $650^{\circ} \mathrm{C}$ and over the same three scan rates, $0.1,0.166$ and $1.0 \mathrm{mV} / \mathrm{s}$. The reference electrode, $\mathrm{Ag} /$ $0.95 \mathrm{~mol} \% \mathrm{AgCl}$ was housed in glass rather than mullite otherwise the three electrode cell was identical to that used for the LiCl-KCl study. Both anodic and cathodic tests were conducted over the same range of overpotential as the PDS in $\mathrm{LiCl} / \mathrm{KCl}$ tests.

\subsection{Analytical Methods}

The samples obtained from the uranium electrodes were divided into two lots, with one fraction being washed in water to remove salt from the metal. The metal portions were then dissolved in acid and both portions (i.e., salt solution and acid solution) were examined for elemental composition using inductively coupled plasma mass spectroscopy (ICP-MS). Portions of the remaining original powdered samples were mounted onto glass discs using double sided tape and sealed using plastic wrap. These sealed samples were then examined with X-ray diffraction (XRD) to determine the identity of the phases present. The electrorefined anode, originally $6 \mathrm{~mm}$ in diameter, was sectioned axially and radially after the conclusion of potentiodynamic testing in $\mathrm{LiCl}-$ $\mathrm{KCl}$, mounted in quick setting acrylic, carbon coated and examined using a scanning electron microscope in an effort to obtain a qualitative understanding of the phenomena occurring at the surface. A portion of the material obtained from the counter electrode used in the preliminary experiments was pressed onto carbon tape mounted on an $\mathrm{Al}$ disc, carbon coated and examined using a scanning electron microscope.

\subsection{Electrochemical Testing}

\section{Results}

A film was observed to form on the uranium anode during the potentiodynamic tests, which detrimentally affected the performance of the electrochemical cell at overpotentials greater than approximately $50 \mathrm{mV}$. Figure 2 shows the uranium working electrode, originally $6 \mathrm{~mm}$ in diameter, after all of the potentiodynamic tests in the eutectic were completed including the final test at the $0.01 \mathrm{mV} / \mathrm{s}$ scan rate. The electrode can be supposed to have contained an internal void prior to testing as it was only $54 \%$ of the mass of a solid uranium electrode of the same dimension. Post-testing, the internal void was revealed and a perforation in the thin wall of the rod exposed the interior surface, as shown in Figure 2. Some of the salt coating, appearing as a black or dark purple color, has been removed near the site of the perforation leaving a gray metallic patch. The material removed from this patch forms the powder sample analyzed by ICPMS and XRD.

* Corresponding Author at Argonne National Laboratory 9700 S. Cass Ave, Argonne, IL 60439, U.S.A. Tel: +1 6302523239

Email Address: marose@anl.gov 


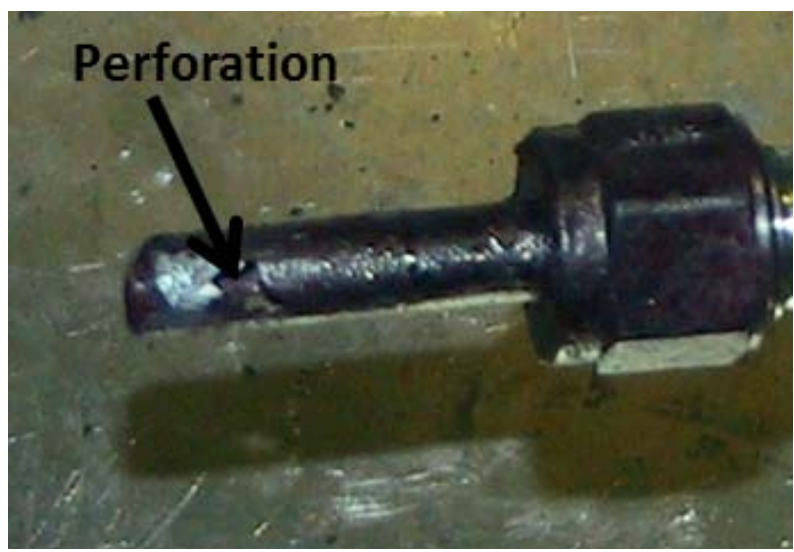

Figure 2: Uranium Working Electrode After Potentiodynamic Testing in LiCl-KCl.

The effect that this material has at the working electrode can be seen in the potentiodynamic response curves, shown in Figure 3 for the $\mathrm{LiCl}-\mathrm{KCl}$ eutectic system. At low temperature, $450^{\circ} \mathrm{C}$, the response shows a decline in achievable current near $50 \mathrm{mV}$, an area in which the current increases with increasing overpotential from $50 \mathrm{mV}$ to 100 $\mathrm{mV}$, a region in which an increase in potential produces no increase in current between 100 and $250 \mathrm{mV}$, and finally a rise in current with overpotentials above $250 \mathrm{mV}$. Similar features were observed for the data collected at $500^{\circ}, 550^{\circ}$ a nd $600^{\circ} \mathrm{C}$. At high temperature, $650^{\circ} \mathrm{C}$, the current rises smoothly with potential towards an asymptote.

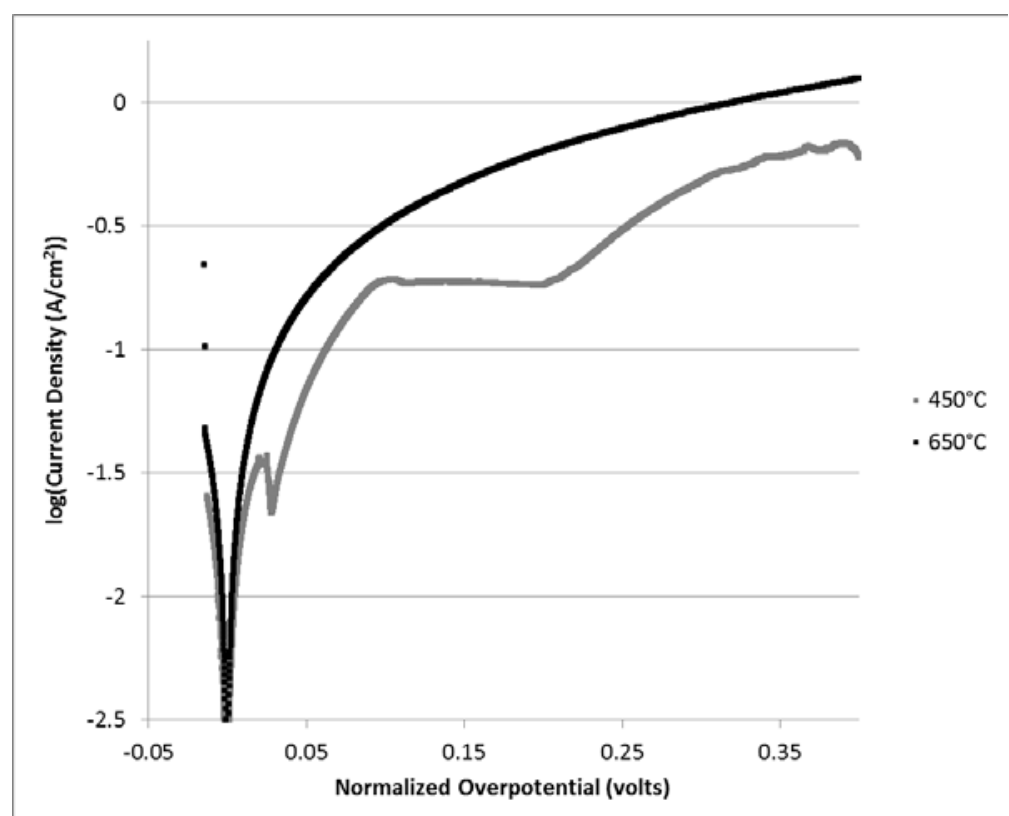

Figure 3: Potentiodynamic Response of Uranium Working Electrode at Two Temperatures at $0.1 \mathrm{mV} / \mathrm{s}$ in $\mathrm{LiCl}-\mathrm{KCl}$.

The potentiodynamic response of the uranium electrode in $\mathrm{LiCl}$ is shown in Figure 4. The major experimental difference between the PDS in $\mathrm{LiCl}$ and the eutectic was the housing used for the reference electrode. To be sure this difference in cell

* Corresponding Author at Argonne National Laboratory 9700 S. Cass Ave, Argonne, IL 60439, U.S.A. Tel: +1 6302523239

Email Address: marose@anl.gov 
structure was not influencing the PDS data, a glass housed reference electrode was used for a PDS in eutectic salt at $500^{\circ} \mathrm{C}$ and compared to data for a mullite housed reference electrode. Satisfactory agreement was observed between the two PDS scans and reference electrode performance.

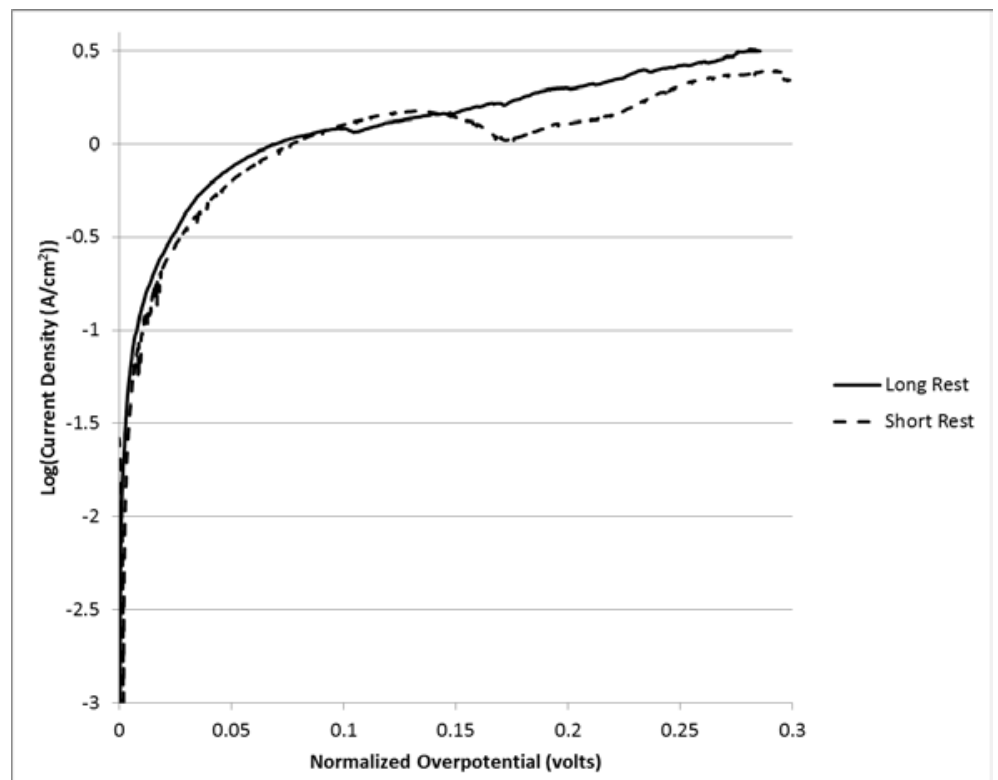

Figure 4: Potentiodynamic Response of a Uranium Working Electrode at $650^{\circ} \mathrm{C}$ in $\mathrm{LiCl}$ $\sim 5 \mathrm{~mol}_{\%} \mathrm{UCl}_{3}$ With Short and Long Rest Periods.

Figure 4 shows the response of the uranium electrode for two rest periods or time at open circuit between scans. The solid line is the response of the working electrode after a rest of at least 3 hours (labeled long rest) and the dashed line is the response of sequential PDS with rests of only 1000 seconds (labeled short rest) between scans. The PDS taken sequentially with short rests exhibits a reduction in current at greater than $0.125 \mathrm{~V}$ overpotential and a slow rise in current above $0.175 \mathrm{~V}$ overpotential. The PDS taken with a long rest of at least three hours exhibits a very minor reduction in current before continuing to rise in current density with increasing overpotential.

\subsection{Analytical Testing}

Three powder samples collected from uranium electrodes were analyzed using ICP-MS. Qualitatively, the data show that the iron contamination due to the sampling method was minimal at no more than $2.3 \mathrm{~mol} \%$ of the samples. The samples taken from counter electrodes that were placed under anodic conditions consisted of 79.7 and 100 mol\% salt, and the sample from the working electrode in the potentiodynamic tests consisted of $96.6 \mathrm{~mol} \%$ salt, which indicates the sampling method was successful in capturing the material without excessive removal of the metallic electrode. The percentages of $\mathrm{UCl}_{3}$, in the salt portions of the samples, were 1.23 and $6.63 \mathrm{~mol} \%$ for the preliminary experiment samples and $2.77 \mathrm{~mol} \%$ for the sample from the working electrode used in the potentiodynamic tests. The two samples that yielded lower $\mathrm{UCl}_{3}$

* Corresponding Author at Argonne National Laboratory 9700 S. Cass Ave, Argonne, IL 60439, U.S.A. Tel: +1 6302523239

Email Address: marose@anl.gov 
concentration values were analyzed after long wait times in uncontrolled atmospheres and may be subject to error due to the hygroscopic nature of the material.

Two sealed powder samples of the material removed from the electrodes by abrasion with a steel file were mounted on glass discs, examined using XRD and the results are shown in Figure 5. Also shown in Figure 5 are known positions of diffraction lines for substances potentially present in the material. These known positions were obtained from a library of diffraction patterns published by the International Centre for Diffraction Data [7]. XRD patterns for compounds containing $\mathrm{Cl}$ with some combination of $\mathrm{Li}, \mathrm{K}$, or $\mathrm{U}$ were compared to the resulting data including species with several different valence states of uranium such as $\mathrm{K}_{2} \mathrm{UCl}_{5}(+3)$ andK $\mathrm{UCl}_{6}(+4)$.

Diffraction patterns for species containing $\mathrm{Pu}$ and $\mathrm{Th}$ were examined in cases where the pattern for $\mathrm{U}$ did not exist in the database for example, $\mathrm{K}_{3} \mathrm{Pu}_{5} \mathrm{Cl}_{18}$ as an analog for $\mathrm{K}_{3} \mathrm{U}_{5} \mathrm{Cl}_{18}$. The diffraction patterns for oxygen-bearing phases such as $\mathrm{UOCl}, \mathrm{UO}_{2}$ and $\mathrm{U}_{3} \mathrm{O}_{8}$ were also compared to the diffraction pattern from the salt samples. The lack of patterns for the oxygen-bearing phases in the observed pattern indicates that oxygen contamination was minimal in the tests and in preparing the samples for and during XRD analysis. The patterns that best matched the data are shown in Figure 5.

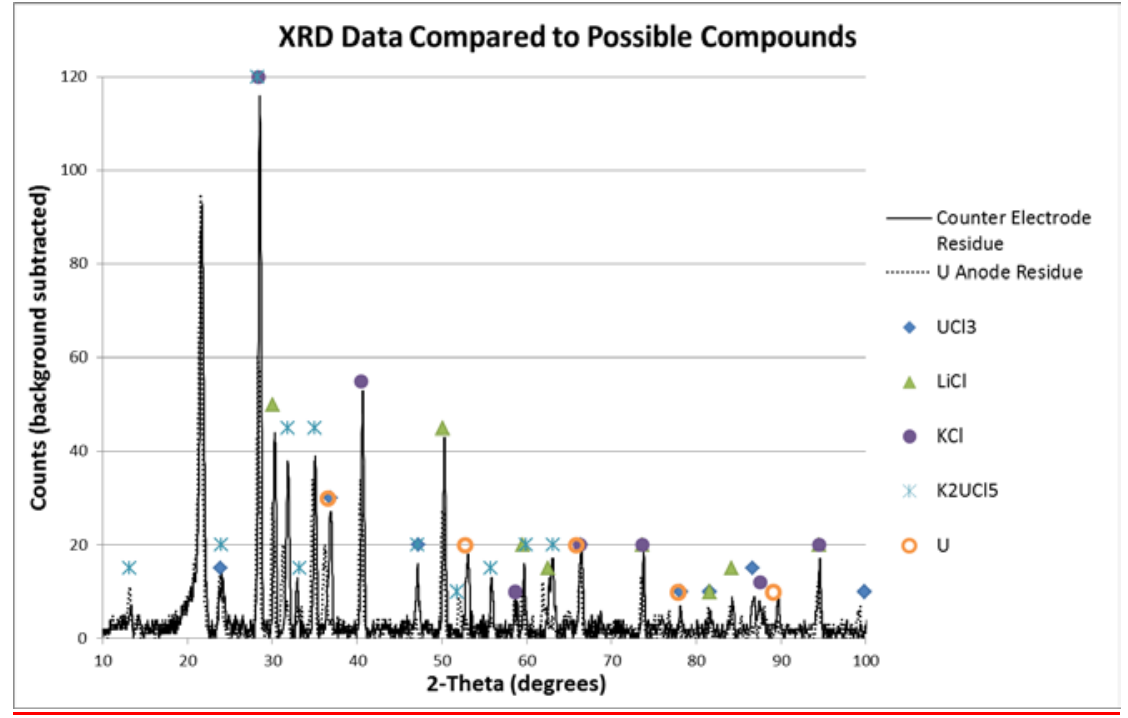

Figure 5: X-Ray diffraction Patterns for Two Powder Anodic Samples in Comparison to Known Compounds.

Figure 5 shows that while $\mathrm{LiCl}, \mathrm{KCl}, \mathrm{UCl}_{3}$ and $\mathrm{U}$ are present, as expected, some of the peaks are not associated with those four phases. Those peaks correspond to the pattern for $\mathrm{K}_{2} \mathrm{UCl}_{5}$, particularly those in the $10-70^{\circ}$ two-theta region. A sharp peak occurs at just over $20^{\circ} \mathrm{t}$ wo-theta, which results from the sample holder as it also occurs in diffraction patterns of blank sealed sample slides. The largest peak at $28^{\circ}$ two-theta can be explained by both $\mathrm{KCl}$ and $\mathrm{K}_{2} \mathrm{UCl}_{5}$.

Scanning electron microscope images were obtained for the powder sample from the preliminary experiments and from the radial and axial cross sections of the hollow uranium rod produced by potentiodynamic testing of the uranium working electrode from

* Corresponding Author at Argonne National Laboratory 9700 S. Cass Ave, Argonne, IL 60439, U.S.A. Tel: +1 6302523239

Email Address: marose@anl.gov 
the $\mathrm{LiCl}-\mathrm{KCl}$ studies. These images are shown in Figure 6. The top two images in Figure 6 are radial cross sections of the hollow rod, with a back scattered electron (BSE) image on the left and a scanning electron (SE) image on the right. The BSE image shows the densest material in the lightest color, revealing that significant quantities of uranium exist within the thin wall of the hollow electrode. The SE image shows that the dissolution occurred non-uniformly from both the inner and outer surfaces of the hollow rod.

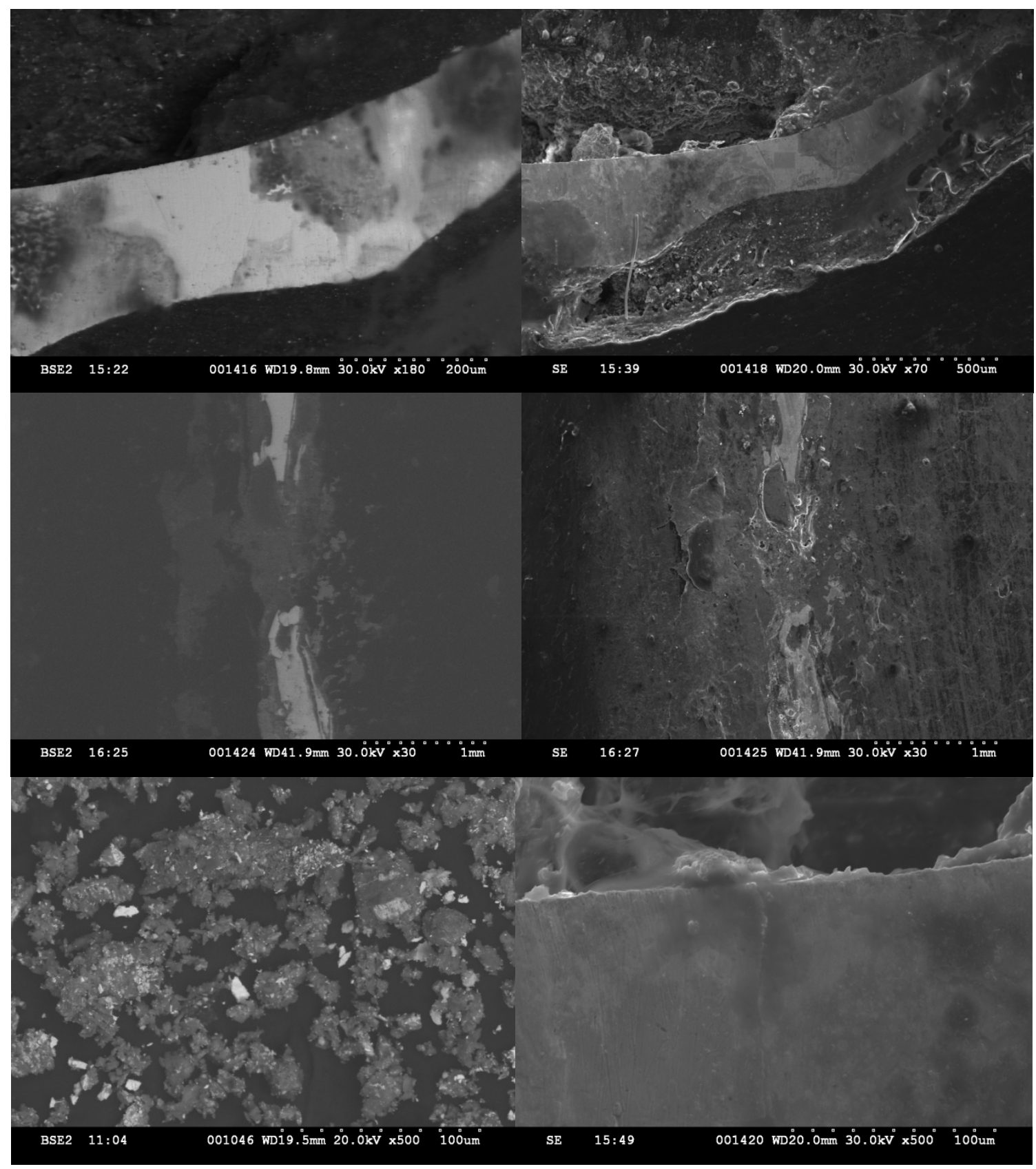

Figure 6: (left to right, top to bottom) i)BSE of Radial Cross Section of 6mm U Rod After PDS. ii)SEM of Radial Cross Section of $6 \mathrm{~mm} U$ Rod After PDS. iii) BSE of Axial Cross Section of $6 \mathrm{~mm}$ U Rod After PDS. iv) SEM of Axial Cross Section of 6mm Rod After

* Corresponding Author at Argonne National Laboratory 9700 S. Cass Ave, Argonne, IL 60439, U.S.A. Tel: +1 6302523239

Email Address: marose@anl.gov 
PDS. v)BSE of Powder Sample Obtained From Preliminary Experiments. vi)SEM of Crack in 6mm U Rod After PDS.

The center two images are from the axially cross sectioned hollow uranium working electrode. It is clear from the BSE image, on the left, that a hole exists in the wall of the uranium rod and is filled with salt, indicated by the medium gray shade material. The bottom right image is a close up of the radially sectioned hollow rod that reveals a crack in the uranium metal. At the surface of the crack clumps of material have accumulated. Elemental analysis was conducted at discrete points along the surface of the metal salt interface in all of the images and the resulting uranium concentrations vary from $1.6 \mathrm{to} 28.6 \mathrm{~mol} \%$. Elemental analysis also determined that the portions of the images appearing to be metallic were on average $90 \mathrm{~mol} \%$ uranium. The materials being examined were not good electronic conductors at room temperature and therefore $30 \mathrm{kV}$ of potential was required to effectively examine the surfaces. This requirement leads to a potential source of error in the elemental analysis obtained from the SEM images as discrete points measured at low magnifications encompass volumes larger than intended due to the high potential applied. Thus, the $10 \mathrm{~mol} \%$ of the metallic region not identified as uranium may be the carbon coating applied to the surface of the sample or other surrounding non-metallic materials.

The bottom left image in Figure 6 is a BSE image of the powder sample obtained from the uranium counter electrode used in preliminary experiments. The BSE image shows a highly non-uniform granular material with spots of highly dense material, likely metallic uranium, scattered throughout. This result is in agreement with the ICP-MS data that showed this sample to be $79.7 \mathrm{~mol} \%$ salt.

\section{Discussion}

\section{1 $\mathrm{LiCl} / \mathrm{KCl} / \mathrm{UCl}_{3}$ System Response at $450^{\circ} \mathrm{C}$}

The material observed at uranium containing anodes by researchers has been reproduced and its effect on the polarization of uranium anodes closely studied. Figure 3 shows that at temperatures typical for electrorefining, formation of the material produces a reduction in current density with increasing overpotential. This reduction occurs at less than $50 \mathrm{mV}$. The current density growth then stalls over a wide range of overpotential spanning $100 \mathrm{mV}$ to nearly $250 \mathrm{mV}$, creating a passive region. Passivation is the reduction in current density with a rise in overpotential usually due to a film or layer of passive or insoluble material at the anode [8]. In the observed PDS response, the current density begins to rise with overpotential again after this passive region.

One explanation for the polarization behavior observed is that as $\mathrm{U}^{3+}$ ions are dissolved from the surface of the electrode, they collect in the diffusion layer faster than they can diffuse out of the layer creating a high concentration of $\mathrm{U}^{3+}$ in the layer. Examination of phase diagrams for the ternary $\mathrm{LiCl} / \mathrm{KCl} / \mathrm{UCl}_{3}$ system shows that at the lowest temperature examined, $450^{\circ} \mathrm{C}$, and at $\mathrm{UCl}_{3}$ concentrations over $\sim 6 \mathrm{~mol} \%$, the $\mathrm{K}_{2} \mathrm{UCl}_{5}$ phase will be present as a solid [9]. The presence of $\mathrm{K}_{2} \mathrm{UCl}_{5}$ is confirmed by the XRD data produced from room temperature samples of anode material. Thus, it is possible that complex formation leading to the formation of $\mathrm{K}_{2} \mathrm{UCl}_{5}$ is occurring at the

* Corresponding Author at Argonne National Laboratory 9700 S. Cass Ave, Argonne, IL 60439, U.S.A. Tel: +1 6302523239

Email Address: marose@anl.gov 
interface leading to partial blockage of the electrode surface. The flat region of current density seen between 100 and $250 \mathrm{mV}$ in Figure 3 could be the result of a majority of the surface becoming blocked by the solid material and the passage of ions through it becoming diffusion controlled, which is independent of the applied overpotential.

In order for solid $\mathrm{K}_{2} \mathrm{UCl}_{5}$ to form at $450^{\circ} \mathrm{C}$, the concentration of $\mathrm{UCl}_{3}$ at the anode surface must rise above $\sim 6 \mathrm{~mol} \%$ according to the phase diagram for the ternary system [9]. The elemental composition of solid salt samples from the surface of the uranium anodes post- PDS testing showed $\mathrm{UCl}_{3}$ concentrations of $1.23,6.63$ and $2.77 \mathrm{~mol} \%$. These samples were collected in such a way that both the diffusion layer and a portion of the salt surrounding the diffusion layer were collected. There were significant potential sources of error in the analysis of the samples as well. The samples at 1.23 and 2.77 mol\% $\mathrm{UCl}_{3}$ were held in an uncontrolled atmosphere prior to analysis and may have oxidized or reacted with water vapor creating discrepancies in the initial mass of the samples used to calculate concentration. The samples were then washed to separate salt from metallic or oxide components and the salt portion analyzed. Washing and dissolution of the samples may have been incomplete in the two suspect samples leading to further error in the concentration values. This analytical data does not rule out the possibility that portions of the anode surface or the thin diffusion layer adjacent to the anode surface may have $\mathrm{UCl}_{3}$ concentrations higher than 6 mol\%. In cracks and crevices in the uranium surface this possibility is even more likely as diffusion away from such areas is reduced.

The idea that $\mathrm{UCl}_{3}$ concentration may vary across the surface of the anode, obtaining maximum concentration in cracks and crevices is supported by the SEM data shown in Figure 6. The elemental analysis obtained from the images reports variation from 1.6 to as much as $28.6 \mathrm{~mol} \% \mathrm{U}^{3+}$ along the anode surface, well in excess of the necessary $\sim 6 \mathrm{~mol} \%$. It should be noted though that due to the low electrical conductivity of the salt material at room temperature, high voltages were necessary to observe the surface. Therefore, the region measured during elemental analysis was large and could encompass a larger volume than intended including surrounding materials in the analysis. This potential source of error in the elemental analysis of the SEM images is particularly possibly in images at high magnification.

Despite the sources of error, the data show that there is a possibility that locations along the surface of the anode, if not the entire surface, experience high enough concentrations of $\mathrm{U}^{3+}$ or $\mathrm{UCl}_{3}$ to form solid $\mathrm{K}_{2} \mathrm{UCl}_{5}$. What is unclear from the data is whether it forms at discrete locations or evenly across the surface, and whether it dissolves or cracks due to internal stress at high overpotentials. These issues could be addressed with a set of carefully designed experiments.

\section{2 $\mathrm{LiCl} / \mathrm{KCl} / \mathrm{UCl}_{3}$ System Response at $650^{\circ} \mathrm{C}$}

To further support the explanation presented for the PDS response curve observed at $450^{\circ} \mathrm{C}$, the response curve observed at $650^{\circ} \mathrm{C}$ shows simple concentration polarization with no reduction in current density. This result supports the idea that the response at lower temperatures is caused by formation of solid $\mathrm{K}_{2} \mathrm{UCl}_{5}$ that is possibly due to an increased concentration of $\mathrm{U}^{3+}$ ions in the diffusion layer. The congruent melting temperature of $\mathrm{K}_{2} \mathrm{UCl}_{5}$, or the temperature above which the ternary phase melts, is

* Corresponding Author at Argonne National Laboratory 9700 S. Cass Ave, Argonne, IL 60439, U.S.A. Tel: +1 6302523239

Email Address: marose@anl.gov 
$626^{\circ} \mathrm{C}$, thus at $650^{\circ} \mathrm{C}$ the system should be entirely liquid and noe ffects of solid formation should be observed [10]. The absence of the response features observed at low temperature in the $650^{\circ} \mathrm{C}$ response curve suggests that the features observed at low temperature could be caused by solid formation, which is absent at the higher temperature.

\section{3 $\mathrm{LiCl} / \mathrm{UCl}_{3}$ System Response at $650^{\circ} \mathrm{C}$}

The PDS response of a uranium electrode in the $\mathrm{LiCl} \sim 6 \mathrm{~mol}^{\circ} \mathrm{UCl}_{3}$ electrolyte also supports the explanation for the observed PDS behavior in eutectic salt. If the system is allowed to rest between tests for a minimum of three hours, the response shows simple concentration polarization with no reduction in current density with rising overpotential much like the response of the ternary system at $650^{\circ} \mathrm{C}$. However, if the system is allowed to rest for 1000s or less between scans, the response shows a reduction in current density near $150 \mathrm{mV}$. The fact that this feature only appears if the system is at open circuit for less than $1000 \mathrm{~s}$, suggests that the concentration of $\mathrm{U}^{3+}$ ions build up near the electrode surface, which with time under no applied potential dissipates. It is possible that this gradient could yield, given enough time under applied potential, a $\mathrm{UCl}_{3}$ concentration above which $\mathrm{UCl}_{3}$ is insoluble as is suspected to be the case in the ternary system at low temperatures, though the eutectic case is complicated by ternary phase formation as well.

Examining the phase diagram for the $\mathrm{LiCl}-\mathrm{UCl}_{3}$ system shows that at $650^{\circ} \mathrm{C}$ the minimum $\mathrm{UCl}_{3}$ concentration to form solid $\mathrm{UCl}_{3}$ is $40 \mathrm{~mol} \%$ [10]. This fact may explain the reason that the reduction in current density is only seen in sequentially run tests with limited rests. A large amount of uranium must be dissolved and enter the diffusion layer without being allowed to dissipate to obtain the required concentration of $\mathrm{U}^{3+}$ for $\mathrm{UCl}_{3}$ precipitation to occur. No initial reduction in current density in the $\mathrm{LiCl} / \mathrm{UCl}_{3}$ response curve, shown in Figure 4, is observed at overpotentials under $50 \mathrm{mV}$, as was observed in the eutectic system. If in the eutectic system this behavior is caused by the onset of $\mathrm{K}_{2} \mathrm{UCl}_{5}$ formation, then it is logical that this initial reduction does not appear in the $\mathrm{LiCl} / \mathrm{UCl}_{3}$ response curves.

\subsection{Implications for Electrorefining}

The residue or he el seen in electrorefiner anodes has traditionally had a high uranium concentration thus, lowering the yield and throughput of electrorefining. Based on the evidence gathered here, this residue or heel can be explained by an enrichment of $\mathrm{U}^{3+}$ ions to such an extent that the solubility limit for $\mathrm{UCl}_{3}$ or in the case of the eutectic salt $\mathrm{K}_{2} \mathrm{UCl}_{5}$ is reached. Once this solubility limit is reached, portions, or all, of the electrode surface is blocked, slowing or preventing uranium from dissolving. Maintaining the eutectic salt at $650^{\circ} \mathrm{C}$ avoids formation of solid $\mathrm{K}_{2} \mathrm{UCl}_{5}$ and prevents the passivation of the surface.

The work done with uranium alloy anodes has shown similar current density reduction during operation. Iizuka explains this phenomenon as resulting from the formation of multiple diffusion layers and postulated the formation of insoluble $\mathrm{UCl}_{3}$ in the pores of the porous zirconium layer [2]. This explanation may be true but Iizuka neglects to consider the possibility that increased uranium ion concentration at the surface of the alloy may also produce insoluble products such as $\mathrm{K}_{2} \underline{\mathrm{UCl}}_{5}$, which present a barrier

* Corresponding Author at Argonne National Laboratory 9700 S. Cass Ave, Argonne, IL 60439, U.S.A. Tel: +1 6302523239

Email Address: marose@anl.gov 
to dissolution. By testing the same alloy system at $650^{\circ} \mathrm{C}$ rather than $500^{\circ} \mathrm{C}$, it would be possible to discover if the current reduction seen with uranium alloys is caused by an alloy phase change as uranium is removed from the material or by solid salt-layer formation or both.

\section{Conclusions}

A buildup of material at the anode during electrorefining of uranium metal has been observed during this and other studies. The potentiodynamic response of a uranium anode in both $\mathrm{LiCl}$ and $\mathrm{LiCl} / / \mathrm{KCl}$ eutectic observed in this study suggests that as the $\mathrm{U}^{3+}$ concentration increases in the layer surrounding the electrode, electrode blocking occurs resulting in the reduction in current density with increasing overpotential. As the layer becomes concentrated in $\mathrm{U}^{3+}$ to such a degree that the solubility limit for $\mathrm{UCl}_{3}$ is exceeded or in the case of the eutectic salt $\mathrm{K}_{2} \mathrm{UCl}_{5}$ formation occurs at the electrode surface and passivation of the electrode occurs. XRD analysis of room temperature samples of the material obtained from eutectic salt and phase diagram analysis indicates that in the eutectic salt the identity of the material is likely solid $\mathrm{K}_{2} \mathrm{UCl}_{5}$. While in the $\mathrm{LiCl} / \mathrm{UCl}_{3}$ system, phase diagram analysis suggests it is likely $\mathrm{UCl}_{3}$. SEM and ICP-MS analysis of the material formed in eutectic salt suggests that the material does not form uniformly, as the concentration required to form solid $\mathrm{K}_{2} \mathrm{UCl}_{5}$ is not sufficient except at cracks or crevices or possibly only in the narrow diffusion layer. In the ternary system above $650^{\circ} \mathrm{C}, \mathrm{K}_{2} \mathrm{UCl}_{5}$ does not affect the potentiodynamic response of the electrode because the congruent melting temperature of $\mathrm{K}_{2} \mathrm{UCl}_{5}$ is $626^{\circ} \mathrm{C}$.

\section{Acknowledgments}

The authors acknowledge the technical discussion of this paper with Perry Motsegood and Magdalena Tylka. The authors also acknowledge Terry Cruse for his help in SEM sample preparation and analysis. This work was supported by the U.S. Department of Energy, National Nuclear Security Administration's (NNSA's) Office of Defense Nuclear Nonproliferation, under Contract DE-AC02-06CH11357. Argonne National Laboratory is operated for the U.S. Department of Energy by UChicago Argonne, LLC.

\section{References}

[1] M. Iizuka, T. Omori, and T. Tsukada. J. of Nucl. Sci. and Tech. 47(2010) 244-254.

[2] Iizuka M., Kinoshita K., and Koyama T. J. of Phys. and Chem. of Solids. 66(2005) 427-432.

[3] Van Kleeck M., Willit J., Williamson M.A., and Fentiman A.W. "GLOBAL 2013: International Fuel Cycle Conference. Salt Lake City, UT. Sept. $29^{\text {th }}$ - Oct. $3^{\text {rd }}, 2013$.

[4] Van Kleeck, M.A., Figueroa, J., Blaskovitz, R., Willit, J., Williamson, M.A., and Fentiman, A.W. "2012 International Pyroprocessing Research Conference. Fontana, WI, Aug. 26-30 ${ }^{\text {th }}, 2012$.

[5] Iizuka M., Akagi M. and Omori T. Nucl. Tech. 181(2013) 507-525.

* Corresponding Author at Argonne National Laboratory 9700 S. Cass Ave, Argonne, IL 60439, U.S.A. Tel: +1 6302523239

Email Address: marose@anl.gov 
[6] M.A. Rose, M.A. Williamson, J. Willit. ECS Electrochemistry Letters. 4(2015) C5C7.

[7] Powder Diffraction File Database. International Centre for Diffraction Data. Newton Square, PA. www.icdd.com. 2014.

[8] L. Epelboin and M. Keddam. Proceedings of the Fourth International Symposium on Passivity: Passivity of Metals. The Electrochemical Society, Princeton, NJ. 1978. 184-222.

[9] A. Nakayoshi, S. Kitawaki, M. Fukushima, T. Murakami and M. Kurata. J. Nucl. Mater. 441(2013) 468-472.

[10] S. Gosh, B. Prabhakara Reddy, K. Nagarajan, and K.C. Hari Kumar, CALPHAD 45(2014) 11-26.

* Corresponding Author at Argonne National Laboratory 9700 S. Cass Ave, Argonne, IL 60439, U.S.A. Tel: +1 6302523239

Email Address: marose@anl.gov 